\title{
Feto-maternal outcome study in hypertensive disorders of pregnancy: primigravida vs multigravida
}

\author{
Jaydeb Mandal*, Dibyendu Roy
}

Department of Obstetrics and Gynaecology, Malda Medical College, West Bengal, India

Received: 03 February 2021

Accepted: 19 February 2021

\section{*Correspondence:}

Dr. Jaydeb Mandal,

E-mail: jaydebmandal013@gmail.com m

Copyright: (c) the author(s), publisher and licensee Medip Academy. This is an open-access article distributed under the terms of the Creative Commons Attribution Non-Commercial License, which permits unrestricted non-commercial use, distribution, and reproduction in any medium, provided the original work is properly cited.

\begin{abstract}
Background: Approximately 7-10\% of all pregnancies are complicated by some form of hypertensive disorders. Hypertensive disorders of pregnancy (HDP) are major cause of maternal morbidity and mortality as well as fetal complications. This study is aimed to determine and compare the maternal and perinatal outcomes of hypertensive pregnancies in between primigravida and multigravida.

Methods: After taking college ethical committee permission a prospective comparative study was done in our medical college from January 2017 to April 2017 with 300 women having HDP from 3658 admitted patients in that time. They were enquired and followed up as per questionnaire till their discharge from the hospital. Among study women 174 women were primigravida, 126 were multigravida. The prevalence of maternal events and complications like eclampsia, IUGR, preterm labour (PTL), HELLP syndrome DIC, mode of delivery and fetal events like Apgar's score, birth weight were studied and compared among primigravida and multigravida. All the events related to pregnancy outcomes were analyzed statistically.

Results: Our study shows prevalence of HDP was $8.2 \%$ of total admitted patients, of them 58\% were primigravida, $42 \%$ multigravida. Primigravida compared to multigravida had a higher tendency to have IUGR, PTL. DIC is also slightly more in primigravida but placental abruption and PPH were more in multigravida. Fetal outcome study showed babies born with low birth weight is significantly more in primigravida and higher incidence of severe asphyxiated babies were born in primigravida. More than $40 \%$ primigravida were terminated by caesarean section, most of them had emergency indication.

Conclusions: Primigravidas are more sufferer to HDP and its complications. Comprehensive antenatal care at the same time strict vigilance during delivery and quality postnatal care of high risk patients specially primigravida group could significantly reduce maternal morbidity and mortality and improves fetal outcome.
\end{abstract}

Keywords: DIC, Hypertensive disorders of pregnancy, HELLP Syndrome, IUGR

\section{INTRODUCTION}

Hypertensive disorders are the most common medical disorders encountered during pregnancy, occurring in approximately $7-10 \%$ of all pregnancies. ${ }^{1}$ Prevalence of hypertensive disorders of pregnancy (HDP) in India has been reported $6-8 \% .^{2}$ HDP is a major contributor of maternal morbidity as well as mortality leading to 10 $20 \%$ of maternal deaths in developing countries. World health organization (WHO) estimates that at least one women dies every seven minutes from complications of hypertensive disorders of pregnancy. ${ }^{3}$

Basic classification of hypertensive disease in pregnancy include. ${ }^{4}$ Gestational hypertension (GTN) Blood pressure $>140 / 90 \mathrm{~mm}$ of hg after 20 weeks of pregnancy in previously normo-tensive women pre-eclampsia syndrome - Gestational HTN with proteinuria. Eclampsia 
syndrome- women with pre-eclampsia, convulsion/coma that cannot be attributed to another cause. Seizures are generalized and may appear before, during or after labour. Pre-eclampsia superimposed on chronic HTN Chronic underlying HTN is diagnosed in women with documented BP $>140 / 90 \mathrm{~mm}$ of hg before pregnancy or before 20 weeks gestation or both.

Obstetric complications result in large number of babies with low birth weight (LBW), requiring neonatal intensive care. According to WHO5 about $11 \%$ of newborns (12.6 million infants) suffer from LBW at term. Prevalence of LBW newborns in India is $30 \%$ which is highest among South Asian countries. ${ }^{6}$

Pre-eclampsia has long been believed to be a disease of primigravida. The incidence of pre-eclampsia in multiparus women is lower than primiparus women. ${ }^{7}$ Preeclampsia is more likely to occur at both extremes of reproductive age, but is greatest in women younger than 20 years of age. White and African-American women, 15 to 17 years of age,were to have 2.6 times and 2.4 times risk respectively, to develop pre-eclampsia compared to their 25 to 34 years old counterparts. ${ }^{8}$ IUGR is pathological decrease of foetal growth rate which may be due to utero placental insufficiency as a consequence of HDP. Hypertensive disorder complicates IUGR 3 to $7 \%$, oligohydomnimos $4.45 \%$ in developed countries. ${ }^{9}$ HELLP syndrome is an acronym which was coined by Louis Weinstein in 1982 denoting haemolysis, Elevaled Liver Enzymes and Low Platelets.

It is a recognized complication of severe pre-eclampsia, although at times, it can occur in the absence of hypertension and proteinuria. It occurs in $0.2-0.6 \%$ of all pregnancies and in $4-12 \%$ pregnancies complicated by pre-eclampsia. ${ }^{10}$

\section{METHODS}

After taking our college ethical committee permission this prospective comparative study was conducted in our Malda Medical College obstetric department over the period of 4 months from 1st January 2017 to 30th April 2017. In that time total 3658 patients were admitted in antenatal ward and labour room for their pregnancy complications and safe delivery. All women who presented with hypertensive disorders of pregnancy and delivered in this hospital (and antenatal records were complete) were included in this study. All study women were divided into four groups namely, gestational hypertension (GHT), pre-eclampsia, eclampsia and chronic hypertension with superimposed pre-eclampsia based on their antenatal check up records and clinical presentation at admission.

All the women were interviewed as per questionnaire prepared beforehand. After excluding women having all incomplete data entries, the sample size was finalized at 300. Among those 300 patients they were further divided into two gravid groups; primigravida 174 and multigravida 126. Demographic variables included age, booking status (antenatal check up records) economic status, obstetric history included parity status, maternal health status before and during this pregnancy, significant events and detailed information regarding complications occurring antepartum, intrapartum or postpartum were considered in our study. Maternal outcome was recorded which includes mode of delivery and indications of operative delivery, postpartum haemorrhage, HELLP syndrome, IUGR of foetus, placental abruption, PTL, DIC and maternal death. Neonatal outcome such as birth weight, Apgar's score (birth asphyxia) still birth were also recorded. The prevalence of type of hypertension, age group status, all the maternal complications and events related to pregnancy and foetal outcome including birth weight were calculated in primigravida and multigravida. The results were analyzed by modern software, Chi Square test was done. P value $<0.05$ was considered as significant.

\section{RESULTS}

In our study 3658 patients who were admitted in our obstetric department during this study period were examined, of these 300 women had hypertensive disorders of pregnancy of them 174 women( $58 \%$ ) were primigravida and 126 women $(42 \%)$ were multigravida . The incidence of HDP came out to be $8.2 \%$.

Distribution of different types of hypertension in pregnancy (Table 1) depicts that prevalence of preeclampsia and eclampsia are more common in primigravida compare to multigravida ( pre-eclampsia $47.70 \%$ vs $42.85 \%$, eclampsia $35.63 \%$ vs $26.19 \%$ ) respectively, on the other hand GHT are more common in multigravida $(24.60 \%$ vs $15.51 \%)$. Pre-eclampsia super imposed on chronic hypertension are more frequent in multigravida than primigravida $(6.34 \%$ vs $1.72 \%)$ the difference is statistically significant $(\mathrm{p}<0.05)$.

Table 1: Distribution of hypertension type in pregnancy.

\begin{tabular}{|llllll|}
\hline \multirow{2}{*}{ Type of hypertension } & \multicolumn{2}{l}{ Primigravida } & \multicolumn{2}{l|}{ Multigravida } & P value \\
\cline { 2 - 6 } & $\mathbf{N}$ & $\mathbf{\%}$ & $\mathbf{N}$ & $\mathbf{\%}$ & 0.055 \\
\hline Gestational HT & 27 & 15.51 & 31 & 24.60 & 0.4115 \\
\hline Pre eclampsia & 84 & 47.70 & 54 & 42.85 & 0.102 \\
\hline Eclampsia & 62 & 26.19 & 33 & 26.19 & 0.0350 \\
\hline Preeclampsia on ch HT & 03 & 1.72 & 08 & 6.34 & 100 \\
\hline Total & 174 & 100 & 126 & & \\
\hline
\end{tabular}


Table 2: Maternal age distribution of HDP in both groups.

\begin{tabular}{|c|c|c|c|c|c|}
\hline \multirow{2}{*}{ Age group in years } & \multicolumn{2}{|c|}{ Primigravida } & \multicolumn{2}{|c|}{ Multigravida } & \multirow{2}{*}{ P value } \\
\hline & $\mathbf{N}$ & $\%$ & $\mathbf{N}$ & $\%$ & \\
\hline$\leq 20$ & 41 & 23.56 & 10 & 7.93 & \multirow{5}{*}{$<0.00001$} \\
\hline $21-25$ & 82 & 47.126 & 48 & 38.09 & \\
\hline 26-30 & 45 & 25.86 & 42 & 33.33 & \\
\hline$>30$ & 06 & 3.44 & 26 & 20.63 & \\
\hline Total & 174 & 100 & 126 & 100 & \\
\hline
\end{tabular}

Table 3: Maternal complication of HDP women of both groups.

\begin{tabular}{|llllll|}
\hline \multirow{2}{*}{ Maternal coplications } & \multicolumn{2}{c}{ Primigravida } & \multicolumn{2}{c|}{ Multigravida } & P value \\
\cline { 2 - 5 } & $\mathbf{N}$ & $\mathbf{\%}$ & $\mathbf{N}$ & $\mathbf{\%}$ & NS \\
\hline IUGR & 34 & 19.54 & 16 & 12.69 & NS \\
\hline Placental abruption & 03 & 1.72 & 08 & 6.34 & NS \\
\hline HELLP syndrome & 04 & 2.29 & 02 & 1.58 & $<0.05$ \\
\hline Pre term labour & 49 & 28.16 & 23 & 18.25 & NS \\
\hline DIC & 02 & 1.14 & 01 & 0.79 & - \\
\hline PPH & 07 & 4.022 & 10 & 7.93 & - \\
\hline Maternal death & 01 & 0.57 & - & - &
\end{tabular}

Table 4: Mode of delivery study.

\begin{tabular}{|lllll|}
\hline $\begin{array}{l}\text { Mode of } \\
\text { delivery }\end{array}$ & $\mathbf{N}$ & $\mathbf{\%}$ & $\mathbf{N}$ & \% \\
\hline Vaginal & 94 & 54.02 & 85 & 67.46 \\
\hline Instrumental & 10 & 5.74 & 07 & 5.55 \\
\hline $\begin{array}{l}\text { Caesarean } \\
\text { Section }\end{array}$ & 70 & 40.22 & 34 & 26.98 \\
\hline $\begin{array}{l}\text { Emergency } \\
\text { CS }\end{array}$ & 60 & 85.71 & 26 & 76.46 \\
\hline Elective CS & 10 & 14.28 & 08 & 23.53 \\
\hline
\end{tabular}

Demographic features like age group distribution of both study group shows (Table 2) more than $70 \%$ of primigravida mothers were within 25 years age $(23.56 \%$ $+47.12 \%$ ) whereas more than $70 \%$ multigravida mothers were $21-30$ years of age $(38.09 \%+33.33 \%)$. Difference of age group distribution in relation to HDP of both primigravida and multigravda are statistically significant $(\mathrm{p}<0.0001)$.

Maternanal complication study (Table 3) reveals that primigravidas were more sufferer than multigravida in some serious complications like IUGR (19.54\% vs $12.69 \%)$, HELLP syndrome $(2.29 \%$ vs $1.58 \%$, DIC $(1.14 \%$ vs $0.79 \%)$. In some situation multigravidas were more sufferer than primigravidas like placental abruption (6.34\% vs1.72\%) and PPH (7.93\% vs $4.02 \%)$. In case of pre term labour (PTL) statistically significant difference ( $\mathrm{p}<0.05)$ was observed among pmrigravida and multigravida ( $28.16 \%$ vs $18.25 \%)$. One maternal death in primigravida group observed after delivery.

Mode of delivery study (Table 4) shows incidence of caesarean section delivery was fairly common in primigravida mothers than multigravida mothers $(40.22 \%$ vs $26.98 \%$ ). Indications of caesarean section in both groups were mostly emergency indication ( $85.71 \%$ vs $76.47 \%$ ). Incidence of instrumental deliveries of both group were almost same (slightly more than 5\%). One maternal death was recorded from primigravida group.

Neonatal outcome study ( Table 5) depicts severe birth asphyxia (Apgar's score 0-3) were relatively more common in neonates of primigravida mothers than multigravida mothers $(12.06 \%$ vs $9.52 \%)$, so neonatal care unit admissions were more in neonates of primigravida. Incidence of still birth is also more common in primigravida (5/274 vs $2 / 126)$.

Table 5: Neonatal outcome study.

\begin{tabular}{|lllll|}
\hline \multirow{2}{*}{$\begin{array}{l}\text { Apgar's } \\
\text { score }\end{array}$} & \multicolumn{2}{c}{ Primigravida } & \multicolumn{2}{c|}{ Multigravida } \\
\hline $\mathbf{0 - 3}$ & $\mathbf{N}$ & $\mathbf{\%}$ & $\mathbf{N}$ & $\mathbf{\%}$ \\
\hline $\mathbf{4 - 6}$ & 21 & 12.06 & 12 & 9.52 \\
\hline $\mathbf{7 - 1 0}$ & 56 & 32.18 & 37 & 29.36 \\
\hline Still birth & 07 & 55.74 & 77 & 61.11 \\
\hline Fresh & 01 & 0.57 & 02 & 1.58 \\
\hline Macerated & 04 & 2.29 & 02 & 0.0 \\
\hline
\end{tabular}

(Apgar's Score 0- 3 = severe birth asphyxia, score 4-6 = mild birth asphyxia)

Birth weight study (Table 6) reflects that incidence of low birth weight babies $(<2.5 \mathrm{~kg})$ which were more common among newborns of primigravida than multigravida $(31.60 \%$ vs $19.84 \%)$. On the contrarary a good percentage of multigravida mothers delivered $>3.5$ $\mathrm{kg}$ new born ( $25.39 \%$ vs $16.66 \%$ ). Data of table 6 indicates neonatal birth weight difference of both primigravida and multigravida mothers were statistically significant $(\mathrm{p}<0.05)$. 
Table 6: Neonatal Birth weight picture of both groups.

\begin{tabular}{|c|c|c|c|c|c|}
\hline \multirow{2}{*}{$\begin{array}{l}\text { Birth } \\
\text { weight }\end{array}$} & \multicolumn{2}{|c|}{ Primigravida } & \multicolumn{2}{|c|}{ Multigravida } & $\begin{array}{l}\mathbf{P} \\
\text { value }\end{array}$ \\
\hline & No. & Percentage & No. & Percentage & \multirow{4}{*}{0.0357} \\
\hline $\begin{array}{l}<2.5 \\
\text { kgs }\end{array}$ & 55 & 31.60 & 25 & 19.48 & \\
\hline $\begin{array}{l}2.5-3.5 \\
\text { kgs }\end{array}$ & 90 & 51.72 & 69 & 54.76 & \\
\hline $\begin{array}{l}>3.5 \\
\text { kgs }\end{array}$ & 29 & 16.66 & 32 & 25.39 & \\
\hline
\end{tabular}

\section{DISCUSSION}

The prevalence of HTP is different according to the geographic regions of the world and ranges from $1.5 \%$ in Sweden to $7.5 \%$ in Brazil, in India the prevalence of HDP has been reported to be $6-8 \% 2$. This differences can be due to racial reasons, socioeconomic status and some other demographic parameters like age, parity etc. The incidence of HDP in our study was $8.2 \%$, slightly higher than Indian standard and that may be due to maximum high risk mother referral to our tertiary rural medical college. Some literature shows that extreme ages of reproductive life are well known risk factors for HDP, they identified young age as a risk factor for hypertension during pregnancy. ${ }^{11}$ Our study showed $70.68 \%$ primigravida and $46.02 \%$ multigravida and were within 25 years of age (Table 2) and the difference of age group and their parity distribution in relation to hypertensive disorders of pregnancy were statistically significant ( $p$ $<0.00001)$.

Several studies investigated the risk of pre eclampsia which was regarded classically as a disease of first pregnancy so that primigravidity is the risk factor for the development of pre eclampsia, but the multigravida women are also liable for the development of pre eclampsia although the risk factors are less well defined12. In our study prevalence of pre eclampsia and complicated pre eclampsia (eclampsia) is more in primigravida $(83.33 \%$ vs $68.04 \%)$ than primigravida (Table 1).

In comparative maternal outcome study, among primigravida and multigravida (Table 3), significant higher numbers of PTL in case of primigravida $(28.16 \%)$ as compared to their counterparts (18.25\%) were observed and the difference was statistically significant. In case of IUGR our study showed that $19.54 \%$ mothers were in primigravida and $12.69 \%$ were found in multigravida. Acharya et al and Al' Essa et al have also reported the occurrence of IUGR in primiparity is more than multiparity. ${ }^{13,14}$

We observed that pregnancy of multigravida with HDP tend to be complicated by placental abruption is at higher rates compared to primigravida $(7.93 \%$ vs $1.72 \%)$ as well as $\mathrm{PPH}$ (7.93 vs $4.622 \%)$; this was in agreement with result obtained in previous study $(6.7 \%$ vs $1.5 \%)$ for placental abruption and (39\% vs 19\%) for PPH15.

Higher incidence of obstetric complications in primigravida mothers had led to the increased caesarean section (CS) delivery in primigravida (40.22\%) when compared to multigravida $(26.98 \%$ ) ( Table 4 ) and the high rate of emergency caesarean section was explained by increase in the demand for the termination of pregnancies for prevalence of more complicated hypertensive primigravida and also for increased incidence of elective caesarean section for prevention of eclamptic fits and other serious complications like DIC, HELLP syndrome. This study agreed with the results of previous other studies ( $70 \%$ vs $40 \%){ }^{16}$

Table 5 depicts that incidence of neonatal respiratory depression was slightly higher in newborn born of primigravida $(44.24 \%)$ as compared to newborn of multigravida counterparts $(38.88 \%)$. Neonatal admission was more in neonates of primigravida mother due to slightly more incidence of severe respiratory depression ( Apgar's score $<3$ ) in primigravida $(12.06 \%)$ than multigravida mother $(9.52 \%)$.

Preterm labour and intra uterine growth retardation (IUGR) are common occurrences of pre eclampsia and other HDP, both the complications may adversely affect neonatal birth weight specially the neonates born of primigravida (as in our study). Table 6 showed, the neonates born with low birth weight $(<2.5 \mathrm{kgs})$ were more in primigravida than multigravida mother $(31.60 \%$ vs $19.84 \%$ ). Neonatal birth weight difference of primigravida and multigravida were statistically significant $(\mathrm{p}<0.05)$. We observed similar findings from other researchers on incidence of low birth weight neonates born more of primigravida than multigravida. ${ }^{17,18}$

\section{CONCLUSION}

Hypertension in pregnancy including pre eclampsia is not always preventable but eclampsia and other complications are mostly preventable. Many previous studies and our current study showed that primigravida women of extreme ages were more prone to complications of hypertensive disorders, and their neonates are also more susceptible. Hence there is scope for this high risk primigravida group as well as neglected multigravida mothers to incorporate them in health care facilities. There is a need to mobilize and motivate government as well as private health sector to play active role for providing them with adequate and quality health care starting from remote village level to urban areas.

\section{ACKNOWLEDGMENTS}

The authors are thankful to all participant mothers of this study and we really appreciate their active cooperation. They also grateful to college Principal and ethical 
committee members for allowing them to conduct this study in our institution. We express thanks to all the staffs and our junior colleagues who helped us for conducting this study.

\section{Funding: No funding sources}

Conflict of interest: None declared

Ethical approval: The study was approved by the Institutional Ethics Committee

\section{REFERENCES}

1. Wilkins LW. Hypertensive disorders in pregnancy. In Barton JR, et al ( Eds). Manual obstetrics ( 8th edn) Wolters Kluver Health, Philadelphia USA. 2014:183-195.

2. Report of the National high blood pressure education program working group on high blood pressure in pregnancy. Am J. Obstet Gynecol. 2008;183(1):1-22.

3. Arora R, Ganguli RP, Swain S, Oumachigui' A, Rajagram P. Determinants of maternal mortality in eclampsia in India. Aus NZ J Obstet Gynaecol. 1994;34(5):537-9.

4. Marfine JN, Owens MY, Keiser SD. Samdardizes mirsissipi protocol treatment of 190 patients with HELLP slowing disease progression and preventing new major maternal morbidity. Hypertension Pregnancy. 2012;31(1):79.

5. Mercedes de Onis, World Health Organization 2001 .

6. Chakraborty P, Anderson AK. Larchant. J Women Health. 201;20:1373.

7. Dempsey JC, Sorensen TK, Qiu CF, Luthy DA, Williams MA. History of abortion and subsequent risk of pre eclampsia. J Reprod Med. 2003;48(7):509-14.

8. Saftlas AF, Olson DR, Franks AL, Atrash HK, Pokras R. Epidemiology of pre eclampsia and eclampsia in the United States, 1979-1986. Am J Obstet Gynaecol. 1990;163(2):460-5.

9. Romo A, Canceller R, Tobajas J. Pedia for Endocrinal. Review. 2009;6:332.

10. Wolf JL. Liver disease in pregnancy. Med Clin North Am. 1996;80 (5):1167-87.

11. Tavassoli F, Ghasem, M, Ghomian N, Ghorbani, Tavassoli S. Maternal and perinatal outcome in nuliparous women complicated with pregnancy hypertension J Pak Med Assoc. 2010;60(9):707-10.

12. Sibai BM, Gordon R, Thom E. Risk factors for pre eclampsia in healthy nuliparous women: a prospective multicentre study. Am J Obstet Gynecol. 1995;172:642-8.

13. Acharya D, Nagraj K, Nair NS, Bhat HV. Healthy nuliparous women. Indian J Community Med. 2004;29:181.

14. Eissa YA, Aqueel HS, Haque KN, Abobakar AM, Kharfy TM, Khasogy TY. High blood pressure education. Am J Perinatol. 2004;12:278.

15. Caritis S, Sibai B, Hauth J. Predictors of pre eclampsia in women at risk. Am J Obstet. Gynecol. 1998;179:946-51.

16. Hauth JC, Ewel MG, Levine RJ. Pregnancy outcomes in health nulipara who developed hypertension. Obstet Gynaecol. 2000;95:24-8.

17. Nurul A, Abel R, Sampathkumar V. Determinants of maternal mortality in eclampsia in India. Indian $\mathbf{J}$ Peditor. 1993;60:269.

18. Deshmukh JS, Motghase DD, Zodpey SP, Wadhva SK. Determinants of maternal mortality in Eclampsia. Indian Peditor. 1998;35:33.

Cite this article as: Mandal J, Roy D. Feto-maternal outcome study in hypertensive disorders of pregnancy: primigravida vs multigravida. Int $\mathrm{J}$ Reprod Contracept Obstet Gynecol 2021;10:920-4. 